\title{
PENINGKATAN PENDAPATAN MELALUI PELATIHAN PENGOLAHAN WORTEL MENJADI NUGGET SEHAT DAN BERGIZI BAGI IBU RUMAH TANGGA
}

\author{
Febri Nur Pramudya'), Eddy Silamat' ${ }^{1)}$, Gracia Gabrienda'), Adnan²) \\ 1)Agribisnis, Universitas Pat Petulai, Rejang Lebong, Bengkulu, Indonesia \\ ${ }^{2)}$ Agroteknologi, Universitas Pat Petulai, Rejang Lebong, Bengkulu, Indonesia \\ Corresponding author : Febri Nur Pramudya \\ E-mail : febrinurpramudya@gmail.com
}

\section{Diterima 13 Februari 2021, Direvisi 26 Februari 2021, Disetujui 27 Februari 2021}

\begin{abstract}
ABSTRAK
Pengabdian ini bertujuan mengetahui cara pembuatan olahan wortel untuk meningkatkan pendapatan warga desa sekitar dan mengetahui cara memasarkan olahan wortel menjadi nugget yang memiliki nilai jual di masyarakat. Kegiatan pengabdian masyarakat ini menggunakan metode ceramah diskusi dan praktek langsung pembuatan olahan wortel. Kegiatan ini diikuti oleh para lbu rumah tangga yang berjumlah 30 orang. Hasil dari program pengabdian masyarakat ini memberikan pengetahuan dan keterampilan kepada peserta pelatihan untuk mengolah wortel menjadi olahan yang sehat dan juga mempunyai nilai jual tinggi. Pelatihan pengolahan cemilan sehat dari wortel ini berhasil dan efektif dengan persentase $90 \%$ dimana $10 \%$ dari peserta masih fokus dengan usaha yang dijalani sebelumnya. Hasil dari pelatihan ini adalah produk nugget. Setelah pelatihan, peserta telah mulai memasarkan produk tersebut kepada warga sekitar, teman dan kerabat sehingga dapat menambah pendapatan peserta pelatihan.
\end{abstract}

Kata kunci: pengabdian masyarakat; life skills; makanan sehat; olahan wortel

\begin{abstract}
This service aims to find out how to make processed carrots to increase the income of the surrounding villagers and to find out how to market processed carrots into nuggets that have a selling value in the community. This community service activity uses the lecture discussion method and direct practice of making processed carrots. This activity was attended by housewives totaling 30 people. The results of this community service program provide knowledge and skills to training participants to process carrots into healthy preparations that also have a high selling value. The training for processing healthy snacks from carrots was successful and effective with a percentage of $90 \%$ where $10 \%$ of the participants were still focused on their previous business. The result of this training is a product of nuggets. After the training, participants have started marketing the product to local residents, friends and relatives so that they can increase the training participants' income.
\end{abstract}

Keywords: community service; life skills; healthy food; processed carrots

\section{PENDAHULUAN}

Produk pertanian yang memiliki potensi untuk dikembangkan ke arah skala industri adalah buah dan sayur. Buah dan sayuran merupakan produk yang tidak tahan lama dan memiliki harga yang relatif rendah. Banyak petani di Indonesia menjual hasil pertaniannya dalam bentuk produk segar dan tidak melalui diversifikasi produk. Petani juga tidak dapat dalam menentukan harga jual hasil panennya. Petani banyak menjadi lemah secara ekonomi diakibatkan banyaknya tengkulak yang mempermainkan harga, sehingga petani tidak dapat menghasilkan keuntungan maksimal dari hasil panen yang dimilikinya. Diversivikasi produk melalui olahan hasil pertanian salah satunya wortel dapat mendorong pendapatan para petani agar nilai jual dari hasil panen yang dimiliki dapat bernilai lebih baik.

Desa Suban Ayam merupakan salah satu desa yang sebagian besar penduduknya bermata pencaharian sebagai petani. Hasil pertanian utama dari daerah ini adalah sayuran dimana daerah ini salah satu daerah dataran tinggi yang jika ditanami berbagai macam sayur akan tumbuh subur dan menghasilkan.

Salah satu sayuran yang dapat ditemui didaerah ini adalah wortel, dimana jika panen yang dilakukan secara bersamaan akan mempengaruhi harga jual wortel tersebut. Banyak petani setempat menjual wortel dalam bentuk segar sehingga akan berpengaruh terhadap pendapatan yang diperoleh para petani. Hal ini dipengaruhi oelh sifat wortel itu 
sendiri tidak dapat bertahan lama, sehingga walaupun harganya tidak seberapa petani harus rela untuk menjual wortelnya dalam bentuk segar.

Salah satu strategi yang dapat dilakukan untuk peningktan pendapatan petani di Desa tersebut adalah melakukan diversifikasi produk seperti olahan nugget wortel agar sayuran yang dihasilkan dapat bertahan lama dan memiliki nilai jual tinggi. Selain itu jenis sayuran dan buah yang diolah menjadi nugget juga memiliki kandungan gizi yang sangat baik untuk kesehatan sehingga layak untuk dikembangkan. Solusi tentang pengolahan wortel sebagai upaya meningkatkan nilai jual produk wortel, menumbuhkan minat masyarakat agar senang mengkonsumsi wortel. Untuk meningkatkan nilai jual wortel, maka muncul inovasi produk wortel. (Lidiyawati et al., 2013)

Rasa yang dihasilkan dari wortel dan bahan tambahan lainnya tetap terasa nikmat dan masih dapat diterima oleh konsumen. Hal ini didasari dari hasil penelitian yang menunjukkan terdapat perbedaan nyata pengaruh persentase penambahan wortel terhadap tingkat kesukaan warna, bau dan terkstur nugget ayam yang dihasilkan. Tidak terdapat perbedaan nyata pengaruh persentase penambahan wortel terhadap tingkat kesukaan rasa nugget ayam. Sehingga dapat disimpulkan bahwa penambahan wortel sampai $35 \%$ dalam pembuatan nugget ayam masih bisa diterima atau disukai konsumen. (A. A. R. et al., 2020)

Berdasarkan hal tersebut diharapakan olahan wortel tersebut mampu menumbuhkan dan meningkatkan pendapatan warga Desa Suban Ayam. Adapun beberapa tujuan yang ingin dicapai pada kegiatan pengabdian ini adalah: (1) Memberikan pelatihan pembuatan nugget dari bahan baku wortel; (2) Memasarkan olahan wortel menjadi produk nugget yang memiliki nilai jual di masyarakat.

\section{METODE}

Metode yang digunakan dalam kegiatan ini yaitu langsung menuju ke lokasi dan melakukan pemaparan tentang proses pengolahan wortel menjadi nugget. Cara penerapan diberikan dalam bentuk sosialisasi, pelatihan dan demontrasi atau praktek kepada kelompok masyarakat lbu-ibu rumah tangga yang juga bekerja sebagai petani wortel dihalaman rumah warga. Kegiatan ini dilaksanakan di Desa Suban Ayam. Dengan melibatkan warga Desa setempat dan diikuti peserta sebanyak 30 orang. Adapun tahapan pelaksanaan kegiatan yang dilakukan, dapat dilihat pada tabel 1 dibawah ini.

Tabel 1. Tahap pelaksanaan Kegiatan

\begin{tabular}{|c|c|c|c|c|}
\hline No. & Kegiatan & Metode & Target & Peserta \\
\hline 1. & $\begin{array}{l}\text { Memberikan } \\
\text { Ilmu pengetahuan } \\
\text { tahapan/langkah- } \\
\text { langkah pembuatan } \\
\text { nugget wortel }\end{array}$ & Sosialisasi & $\begin{array}{l}\text { Memberikan } \\
\text { pemahaman } \\
\text { tentang proses } \\
\text { pembuatan } \\
\text { nugget wortel }\end{array}$ & $\begin{array}{l}\text { Menyediakan } \\
\text { tempat dan ikut } \\
\text { berpartisipasi } \\
\text { dalam kegiatan } \\
\text { serta } \\
\text { mengkonfirmasi } \\
\text { pada hal-hal } \\
\text { yang kurang } \\
\text { dipahami }\end{array}$ \\
\hline 2. & $\begin{array}{l}\text { Memberikan contoh } \\
\text { (mempraktekkan) } \\
\text { tahapan-tahapan } \\
\text { pembuatan nugget } \\
\text { sayuran }\end{array}$ & Pelatihan & $\begin{array}{l}\text { Memahami } \\
\text { proses } \\
\text { pembutan } \\
\text { nugget } \\
\text { sayuran }\end{array}$ & $\begin{array}{l}\text { Memperhatikan } \\
\text { dengan seksama } \\
\text { proses } \\
\text { pembutan } \\
\text { nugget wortel }\end{array}$ \\
\hline 3. & $\begin{array}{l}\text { Menyiapkan bahan- } \\
\text { bahan untuk pembutan } \\
\text { nugget wortel sesuai } \\
\text { prosedur }\end{array}$ & Pendampingan & $\begin{array}{l}\text { Prosedur yang } \\
\text { diberikan } \\
\text { sebagai acuan } \\
\text { pembuatan } \\
\text { nugget wortel }\end{array}$ & $\begin{array}{l}\text { Mempraktekkan } \\
\text { cara pembuatan } \\
\text { nugget wortel } \\
\text { sesuai prosedur } \\
\text { yang diberikan }\end{array}$ \\
\hline
\end{tabular}


Kegiatan monitoring dilakukan pada saat setelah kegiatan pelatihan ini dilaksanakan. Evaluasi ini dilakukan dengan cara wawancara dan observasi dari antusias ibu rumah tangga yang mengikuti pelatihan kegiatan ini.

\section{HASIL DAN PEMBAHASAN}

\section{Tahapan Persiapan}

Pelaksanaan program pengabdian ini, sebelumnya kami melaksanakan survei terlebih dahulu di Desa Suban Ayam. Observasi dan wawancara diharapkan sesuai dengan kebutuhan warga Desa Suban Ayam. Hasil observasi dan wawancara terhadap anggota tim pengabdian yaitu:

a. Dibutuhkan adanya pelatihan dan pendampingan kemandirian masyarakat dalam mengelola usaha secara mandiri dan professional guna peningkatan SDM bagi ibu rumah tangga di Desa tersebut.

b. Kurangnya pengetahuan masyarakat dalam keterampilan pembuatan produk inovatif yang memiliki nilai jual lebih baik.

\section{Pelaksanaan Kegiatan}

Pelatihan pembutan nugget wortel ini dipandu oleh narasumber yang ahli dalam pembuatan nugget wortel. Materi pelatihan secara umum meliputi modul petunjuk cara pembuatan nugget wortel. Adapun urutan kegiatan pelaksanaan pengabdian pembuatan nugget wortel sebagai bahan ajar dalam pelatihan keterampilan sebagai berikut:

\section{PROSES PEMBUATAN NUGGET}

Proses pembuatan nugget ada bebarapa proses. Dari tahap persiapan alat dan bahan sampai dengan tahap nugget siap untuk dijual. Tahapan proses ini dapat dilihat pada gambar 1 sampai 4 dibawah ini.

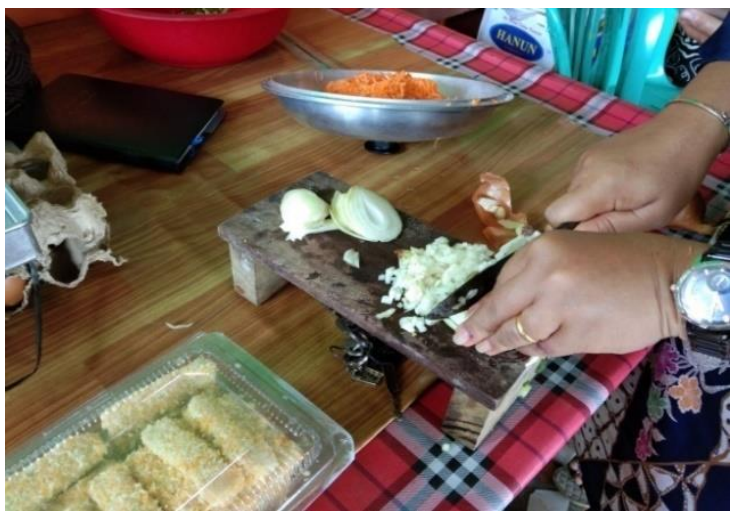

Gambar 1. Tahap persiapan alat dan bahan

Tahapan pada gambar 1 ini adalah menyiapkan alat dan bahan yang harus digunakan diantaranya adalah wortel (parut panjang), daging ayam, merica,bawang Bombay cincang kasar, bawang putih dihaluskan, sagu, telor ayam, Gula pasir secukupnya, Kaldu Aayam, Daun bawang, Garam dan Tepung panir. Alat yang digunakan diantaranya adalah alat kukus, pisau, talenan, alat penggoreng.

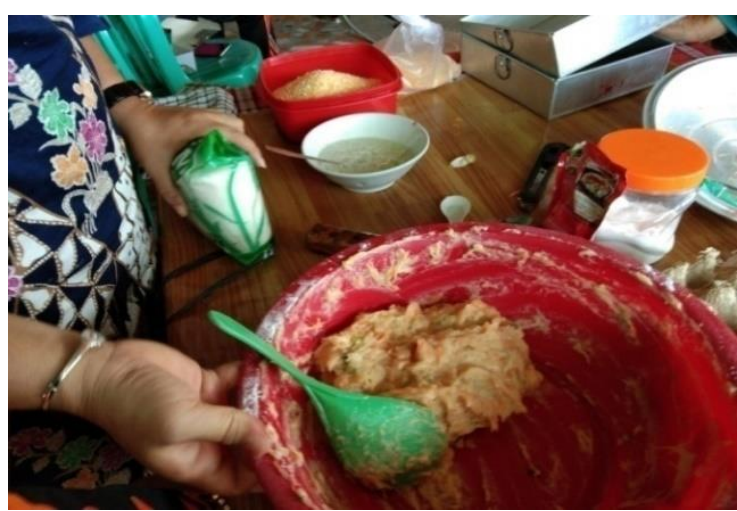

Gambar 2. Tahap pencampuran bahan dan pengukusan

Pada bagian gambar 2 ini, seluruh bahan yang telah disiapkan akan dicampur menjadi satu. Setelah itu akan diletakan pada Loyang yang akan dikukus selama beberapa menit.

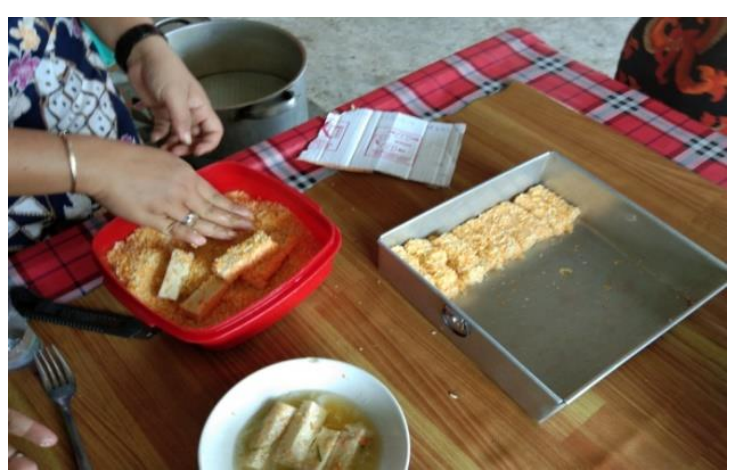

Gambar 3. Tahap pemotongan dan pelapisan tepung roti

Tahapan pada gambar 3 ini adalah tahap akhir pemasakan olahan wortel yang telah dikukus dan siap untuk diltaburi tepung panir agar memberikan penampilan yang menarik saat dijual. Cara mengonsumsinya, nugget ini harus digoreng terlebih dahulu hingga nugget berubah warna menjadi kuning kecokelatan. 


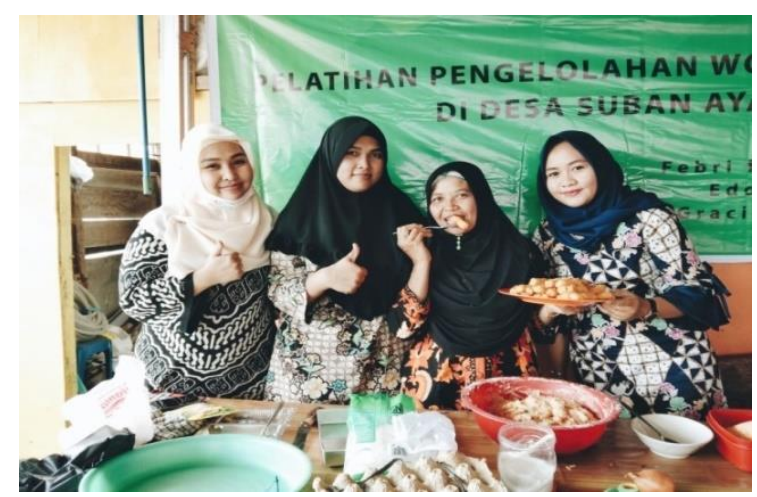

Gambar 4. Tahap nugget yang sudah digoreng dan nugget siap dijual

Tahapan akhir dari gambar 4 proses pembuatan olahan wortel ini adalah pengemasan produk yang dilabeli sehingga mampu membuat produk menajdi menarik dan layak untuk diperjual belikan dikalangan masyarakat. Dimana kemasan ini mempengaruhi minat masyarakat untuk membelinya.

Tentunya nugget ini juga banyak digemari disemua kalangan, apalagi jika nugget wortel ini adalah cemilan yang sehat dan bergizi tanpa bahan pengawet seperti produk nugget lainnya yang dijual oleh berbagai perusahaan ternama. Dengan usaha ekonomi kreatif dari olahan buah dan sayur lokal maka masyarakat mampu menciptakan peluang usaha dari rumah masing-masing.
Demontrasi pada pelatihan ini diharapakan dapat memberi petunjuk pelatihan yang lebih mudah untuk dapat diterima para peserta. Sehingga dari tahap awal persiapan sampai produk siap untuk dijual mampu memberikan petunjuk dan pengetahuan agar dapat dicontoh dan dipraktekan peserta secara mandiri.

\section{Pemasaran Produk Olahan Wortel}

Nugget dipasarkan melalui toko-toko manisan dan mimimaket yang menyediakan kebutuhan pokok dan berbagai cemilan anakanak serta memiliki frezzer yang digunakan untuk tempat penyimpanan nugget. Di lingkungan Desa Suban Ayam banyak tokotoko atau minimarket yang tidak jauh dari Desa untuk melakukan penitipan produk olahan wortel ini. Selain itu juga pemasaran dapat dilakukan melalui sosial media yang dapat dipromosikan setiap saat melalui jasa online.

\section{Biaya}

Biaya adalah salah satu faktor paling penting dalam menyusun suatu usaha bisnis. Perlu adanya asumsi dalam menjalankan usaha produk olahan nugget wortel. Dibawah ini ada tabel 2 dan 3 yang akan merinci biaya yang dikeluarkan dalam menjalankan usaha ini. Dengan asumsi modal awal yang dikeluarkan adalah Rp. 100.000,-

Tabel 2. Biaya Tetap

\begin{tabular}{lccc}
\hline Bahan Baku & Jumlah Barang & Harga Satuan & Jumlah Harga \\
\hline Mika Pelastik & 10 & 1500 & Rp.15.000 \\
\hline Jumlah & & & Rp.15.000 \\
\hline
\end{tabular}

Tabel 3. Biaya Variabel

\begin{tabular}{lccc}
\hline \multicolumn{1}{c}{ Bahan Baku } & Jumlah Barang & Harga Satuan & Jumlah Harga \\
\hline Tepung Panir & $1 \mathrm{Kg}$ & Rp. 20.000,- & Rp. 20.000,- \\
Sagu & $1 / 2 \mathrm{Kg}$ & Rp. $7.000,-$ & Rp.7.000,- \\
Ayam (dada) & $1 \mathrm{Kg}$ & Rp. 30.000,- & Rp.30.000,- \\
Telor & 2 butir & Rp. 1.500,- & Rp. 3.000,- \\
Minyak & 1 liter & Rp. 11.000,- & Rp. 11.000,- \\
Bawang Putih & 10 siung & Rp. 25.000,- & Rp.3.000,- \\
Bawang bombay & 1 siung & Rp. 3.000,- & Rp.3.000,- \\
Wortel & $1 / 2$ Kg & Rp. 5.000,- & Rp. 5.000,- \\
Garam & Secukupnya & Rp. 1000,- & Rp. 1000,- \\
\hline Bahan Baku & Jumlah Barang & Harga Satuan & Jumlah Harga \\
\hline
\end{tabular}




\begin{tabular}{llll}
\hline Daun Bawang & 1 ikat & Rp. 1.000,- & Rp. 1.000,- \\
Kaldu royco & 2 bungkus & Rp. 1.000,- & Rp. 2000,- \\
Merica & 1 bungkus & Rp. 1.000,- & Rp. 1000,- \\
\hline Jumlah & & & Rp. 88.000,-
\end{tabular}

Dalam satu kali produksi dihasilkan sebanyak 10 pack Nugget wortel dan untuk tiap pack harganya adalah Rp.30.000,-.

Jadi dalam sekali produksi menghasilkan

$=$ Rp. $30.000,-\times 10$

$=$ Rp. 300.000,-

Laba bersih = penghasilan- biaya produksi

$$
=\text { Rp. 300.000,- }- \text { Rp. } 100.000
$$$$
=\text { Rp. 200.000,- }
$$

*Laba tersebut didapat dari sekali produksi

Estimasi Laba per bulan

Hari efektif produksi 24 Hari

Penghasilan Produksi/hari

Rp. $300.000,-$

Penghasilan produksi/bulan

$=24$ hari $\times$ Rp.300.000.-

$=$ Rp. $7.200 .000,-$

Laba Bersih/bulan $=$ Penghasilan produksi/bln dikurang biaya operasional/bln

$=(7.200 .000,-)-(24 \times$ Rp.100.000,- $)$

$=$ Rp. $4.800 .000,-$

\section{Tahap Evaluasi Program}

Evaluasi program dilakukan sebanyak 2 kali dimana masing-masing evaluasi dilakukan pada saat selesai pemberian materi dan setelah pelatihan selesai beberapa hari kemudian melakukan monitoring.

Evaluasi pertama dilakukan dalam bentuk diskusi membahas hal kelebihan dan kelemahan dari kegiatan yang dilaksanakan pada hari tersebut dan menerima masukan baik kritik maupun saran dari para peserta. Kegiatan evaluasi ini menghasilkan respon positif dari lbu Rumah tangga dimana mereka sangat berterima kasih dengan adanya pelatihan ini dan berharap akan ada pendampingan selalu di Desa tersebut.

Evaluasi kedua dilakukan setelah beberapa waktu program tersebut terlaksana. Dari evaluasi kedua terdapat dari 30 peserta ada sebanyak 27 peserta sudah memiliki minat dan sudah ada yang mencoba untuk melaksanakan usaha olahan wortel dari pelatihan ini. Hasil evaluasi dilakukan lewat interview dan pengamatan langsung dilapangan.

\section{Kendala yang Dihadapi}

Secara umum dalam pelaksanaan pelatihan dan sosialisasi ini tidak ada kendala selama berlangsungnya kegiatan.
Hanya saja masalah modal awal dalam pembelian alat dan bahan baku menjadi faktor utama ibu- ibu warga desa tersebut dalam memulai usaha. Solusi yang dapat kami berikan adalah mengajukan proposal kepada instansi UMKM yang ada di Kabupaten tersebut guna peningkatan pendapatan bagi warga setempat dan akan kami bantu pendampingan dalam pembuatan proposal ajuannya.

\section{SIMPULAN DAN SARAN}

Kegiatan demontrasi pembuatan produk olahan wortel menjadi nugget berjalan dengan lancar dan sesuai mekanismenya. Pelaksanaan kegiatan tersebut dapat dihitung $90 \%$ berjalan dengan baik dan dapat diterima. Pemasaran produk olahan nugget dapat dititip ke toko manisan dan minimarket serta pemasaran melalui sosial media dan online.

Kegiatan PKM bidang Pengabdian Masyarakat ini diharapakan dapat terus berkembang dan berjalan dengan menggunakan olahan produk lainnya dari bahan baku yang dihasilkan pada Desa Suban Ayam. Diharapkan juga adanya pendampingan dari pemerintah setempat untuk UMKM dapat berdiri di Desa tersebut.

\section{UCAPAN TERIMAKASIH}

Kepada:

1. Lembaga Penelitian dan Pengabdian Masyarakat (LPPM) Universitas Pat Petulai

2. Mitra Desa Suban Ayam, khususnya warga Desa yang mengikuti kegitatan PKM ini.

\section{DAFTAR RUJUKAN}

A. A. R., S., HENDRAWATI, I. A., \& LIKAH, S. (2020). PENGARUH PENAMBAHAN WORTEL TERHADAP TINGKAT KESUKAAN NUGGET AYAM. Majalah IImiah Peternakan, 23(3). https://doi.org/10.24843/mip.2020.v23.i 03.p05

Ardiyanto, M. K. (2020). Analisis Kelayakan Finansial Usahatani Wortel UD Gizi Wortel Di Kabupaten Semarang. Jurnal Social Economic of Agriculture, 9(1). https://doi.org/10.26418/j.sea.v9i1.398 32

IBM UNTUK PETANI SAYUR PENGOLAHAN 
KRIPIK TERONG DAN WORTEL DI

DESA LANJAN KECAMATAN

SUMOWONO KABUPATEN

SEMARANG. (2015). Rekayasa, 13(2).

https://doi.org/10.15294/rekayasa.v13i

2.5607

Lidiyawati, R., Dwijayanti, F., S, N., \& Pradigdo, S. (2013). Mentel (Permen Wortel) Sebagai Solusi Penambah Vitamin A. Jurnal IImiah Mahasiswa, Vol.3 No.1, April 2013, 3(1), 96762.

Muchtadi, T. R., dan Sugiyono. 2014. Prinsip

Proses dan Teknologi Pangan. Alfabeta. Bandung

Rahmiah, A. N., Syam, H., \& Sukainah, A. (2018). ANALISIS MUTU NUGGET IKAN PISANG-PISANG (Casieo crhysozon) DENGAN PENAMBAHAN WORTEL. Jurnal Pendidikan Teknologi Pertanian,

\section{4.} https://doi.org/10.26858/jptp.v4i0.7125

Sari, U. M., Bahri, S., \& Puspitasari, D. J. (2018). KANDUNGAN KAROTEN KERUPUK SIMULASI WORTEL (Daucus carota L.) VARIASI SUHU PENYIMPANAN. KOVALEN: Jurnal Riset Kimia, 4(1). https://doi.org/10.22487/kovalen.2018. v4.i1.10184

Sutanti, S., \& Mutiara, E. (2017). INDUSTRI RUMAH TANGGA STICK WORTEL DI DELI SERDANG. JURNAL PENGABDIAN KEPADA MASYARAKAT, 23(2). https://doi.org/10.24114/jpkm.v23i2.68 73

Toana, S., Rugayah, N., \& Sarjuni, S. (2018). Penambahan Beberapa Sayuran Pada Nugget Ayam. SEMNAS PERSEPSI III MANADO.

Wibowo, S., Arsyad, A., \& Yusdiarti, A. (2017). ANALISIS NILAI TAMBAH DAN PENDAPATAN USAHA PRODUK OLAHAN KERUPUK WORTEL DAN SIRUP WORTEL (Daucus carota L) (Kasus di KWT Citeko Asri Desa Citeko Kecamatan Cisarua Kabupaten Bogor Provinsi Jawa Barat). JURNAL AGRIBISAINS, 1(2). https://doi.org/10.30997/jagi.v1i2.789 